\title{
MATRIX OSTROWSKI INEQUALITY \\ VIA THE MATRIX GEOMETRIC MEAN
}

\author{
Ryosuke Nakayama, Yuki Seo And Reo Tojo
}

Abstract. In this paper, we show a symmetric generalization of the Ostrowski inequality due to Fujii, Lin and Nakamoto. Moreover, we show its two variable extenstion. Inspired by this, we present matrix Ostrowski inequalities via the matrix geometric mean.

Mathematics subject classification (2010): Primary 15A45; Secondary 47A64.

Keywords and phrases: Matrix inequalities, Ostrowski inequality, Cauchy-Schwarz inequality, matrix geometric mean, matrix Cauchy-Schwarz inequality.

\section{REFERENCES}

[1] J. I. FUJII, Operator-valued inner product and operator inequalities, Banach J. Math. Anal., 2 (2008), $59-67$.

[2] M. FUJII, C.-S. Lin AND R. NAKAMOTO, Alternative extensions of Heinz-Kato-Furuta inequality, Sci. Math., 2 (1999), 215-221.

[3] M. Fujimoto And Y. Seo, Matrix Wielandt inequality via the matrix geometric mean, Linear Multilinear Algebra, 66 (2018), 1564-1577.

[4] F. Kubo And T. Ando, Means of positive linear operators, Math. Ann., 246 (1980), 205-224.

[5] D. S. Mitrinović, J. E. PeČArić And A. M. Fink, Classical and New Inequalities in Analysis, Kluwer Academic Publishers, Dordrecht, Boston, London, 1993.

[6] W. Pusz AND S. L. WORONOWICZ, Functional calculus for sesquilinear forms and the purification map, Rep. Math. Phys., 8 (1975), 159-170. 